\title{
Ductus venosus blood velocity in persistent pulmonary hypertension of the newborn
}

\author{
Drude Fugelseth, Torvid Kiserud, Knut Liestøl, Asbjørn Langslet, Rolf Lindemann
}

\begin{abstract}
Aims-To investigate the ductus venosus flow velocity (DVFV) in infants with persistent pulmonary hypertension of the newborn (PPHN); to evaluate the DVFV pattern as a possible diagnostic supplement in neonates with PPHN and other conditions with increased right atrial pressure.

Methods-DVFV was studied in 16 neonates with PPHN on days 1-4 of postnatal life using Doppler echocardiography. DVFV was compared with that in mechanically ventilated neonates with increased intrathoracic pressure, but without signs of PPHN ( $n=11)$; with neonates with congenital heart defects resulting in right atrial pressure $(n=6)$; and with preterm neonates without PPHN (n=46); and healthy term neonates $(n=50)$.

Results-Infants with PPHN and congenital heart defects with increased right atrial pressure were regularly associated with an increased pulsatile pattern and a reversed flow velocity in ductus venosus during atrial contraction. A few short instances of reversed velocity were also noted in normal neonates before the circulation had settled during the first day after birth.

Conclusions-A reversed velocity in the ductus venosus during atrial contraction at this time signifies that central venous pressure exceeds portal pressure. This negative velocity deflection is easily recognised during Doppler examination and can be recommended for diagnosing increased right atrial pressure and PPHN. (Arch Dis Child Fetal Neonatal Ed 1999;81:F35-F39)
\end{abstract}

Keywords: ductus venosus; persistent pulmonary hypertension of the newborn; echocardiography

At birth, the transition from fetal to normal neonatal circulation depends on a rapid decline in pulmonary vascular resistance. In persistent pulmonary hypertension of the newborn (PPHN) pulmonary circulation fails to achieve or sustain low vascular resistance and a reduced pulmonary artery pressure after birth. This syndrome includes various clinical disorders. ${ }^{1}$ The common pathophysiological features include pulmonary hypertension due to high pulmonary vascular resistance, abnormal pulmonary vasoreactivity, right-to-left shunting of blood across a patent ductus arteriosus and/or foramen ovale and severe hypoxaemia. ${ }^{2}$
Several methods for estimation of the pulmonary artery pressure using Doppler echocardiography are currently available. Estimation of the systolic pulmonary artery pressure from the peak velocity of the tricuspid regurgitation jet is the most accurate method, and the easiest to use ${ }^{3{ }^{4}}$ but it is not always suitable.

Postnatally the fetal shunts (ductus venosus, ductus arteriosus, and foramen ovale) close at different intervals. The ductus venosus is normally open for a much longer time than the ductus arteriosus, and it closes later in preterm than in term neonates. ${ }^{56}$ Blood flow velocity recorded in the ductus arteriosus and foramen ovale is currently used to indicate altered pressure gradients. The third shunt, the ductus venosus, is currently not used as a diagnostic tool in the neonatal period. Ductus venosus velocimetry, however, has been extensively investigated and suggested to have valuable diagnostic potentials in fetal life.

This study aimed to investigate the ductus venosus flow velocity (DVFV) in neonates with high pulmonary vascular resistance or PPHN. Secondly, we wanted to examine if a nonnormal DVFV could be a useful addition to Doppler echocardiography for diagnosing neonates with PPHN and other conditions with increased right atrial pressure.

\section{Methods}

Sixteen neonates ( 9 boys, 7 girls) with high pulmonary artery pressure admitted to the neonatal intensive care unit were included in this study (tables 1 and 2). The inclusion criteria were respiratory symptoms of PPHN with cyanosis, and ultrasonographic signs of high pulmonary vascular resistance with extrapulmonary right-to-left or bidirectional shunting across the ductus arteriosus and foramen ovale. The increased pulmonary artery pressure was of differing aetiology and severity, ranging from systemic to suprasystemic. The tricuspid regurgitation peak velocity was $>3.5$ $\mathrm{m} /$ second, which, according to the simplified Bernoulli equation, corresponds to a pressure difference between right ventricle and right atrium of $>49 \mathrm{~mm} \mathrm{Hg}{ }^{3}$ The examination was performed 1-4 days after birth.

Of 10 infants treated with positive pressure mechanical ventilation, two received synchronised intermittent mandatory ventilation and eight high frequency oscillation ventilation.

The protocol was approved by the local ethics committee.

Published studies of term (control group IA) and preterm (control group IB) neonates were used (table 2). ${ }^{5}$ Furthermore, the DVFV in a 
Table 1 PPHN of different aetiologies in 16 neonates studied

\begin{tabular}{|c|c|c|c|c|c|}
\hline Case No & $\begin{array}{l}\text { Gestational age } \\
\text { (weeks) }\end{array}$ & Birthweight (g) & Diagnosis & Ventilation & $\begin{array}{l}\text { Mean airway } \\
\text { pressure }\left(\mathrm{H}_{2} \mathrm{O}\right)\end{array}$ \\
\hline 1 & 35 & 2850 & RDS, PPHN & HFOV & 16 \\
\hline 2 & 34 & 1960 & RDS, PPHN & HFOV & 15 \\
\hline 3 & 35 & 2280 & RDS, pneumothorax, PPHN & HFOV & 12 \\
\hline 4 & 32 & 1470 & $\mathrm{CDH}$, myelominingocele, $\mathrm{PPHN}$ & HFOV & 12.3 \\
\hline 5 & 33 & 2695 & Non-immune hydrops, PPHN & HFOV & 11.4 \\
\hline 6 & 38 & 3600 & Asphyxia, PPHN & HFOV & 16.4 \\
\hline 7 & 39 & 3920 & $\mathrm{CDH}, \mathrm{PPHN}$ & HFOV & 10 \\
\hline 8 & 42 & 4000 & Asphyxia, MAS, PPHN & HFOV & 12 \\
\hline 9 & 33 & 2180 & RDS, PPHN & SIMV & 9 \\
\hline 10 & 34 & 2860 & Trisomy 21, non-immune hydrops, PPHN & SIMV & 7.5 \\
\hline 11 & 34 & 2780 & Trisomy 21, PPHN & Oxygen & \\
\hline 12 & 40 & 2150 & Trisomy 21, PPHN & Oxygen & \\
\hline 13 & 37 & 2140 & $46 \mathrm{XY}(3 \mathrm{p}-), \mathrm{PPHN}$ & Oxygen & \\
\hline 14 & 40 & 4230 & Septicaemia, PPHN & Oxygen & \\
\hline 15 & 35 & 2200 & RDS, PPHN & Oxygen & \\
\hline 16 & 40 & 3990 & Asphyxia, PPHN & Oxygen & \\
\hline
\end{tabular}

RDS = respiratory distress syndrome $\mathrm{CDH}=$ congenital diaphragmatic hernia; $\mathrm{MAS}=$ meconium aspiration syndrome; HFOV $=$ high frequency oscillation ventilation; SIMV $=$ synchronised intermittent mandatory ventilation

group of 13 healthy neonates with comparable gestational age and birthweight as those of the study group was included (control group IC) (table 2). The group therefore included 96 infants ranging in gestational age from 24 to 42 weeks.

To evaluate the influence of positive pressure mechanical ventilation and an increased mean airway pressure on the DVFV, we compared the DVFV in our PPHN group with that in 11 preterm infants treated with positive pressure mechanical ventilation for respiratory distress syndrome, but without signs of PPHN (table 2).

These 11 infants had an open ductus venosus and ductus arteriosus, but with a continuous left-to-right shunt signal across the ductus arteriosus and foramen ovale. Seven were treated with synchronised intermittent mandatory ventilation, one with intermittent mandatory ventilation, and three with high frequency oscillation ventilation.

To evaluate the influence of an increased right atrial pressure on the DVFV, six neonates with congenital heart defects associated with high right atrial pressure were also studied: two with pulmonary valve atresia with intact ventricular septum, one with tricuspid valve atresia, and three with total anomalous pulmonary venous connections (table 2 ).

\section{Methods}

The infants were examined ultrasonographically using a VingMed CFM 800 scanner (Vingmed Sound, Horten, Norway) with a 5
$\mathrm{MHz}$ sector transducer, colour and pulsed Doppler. All the examinations were performed by one observer (DF).

The anatomy of the heart and the great vessels were confirmed by echocardiography. The blood velocity of the ductus venosus was measured at the inlet from the portal vein by a right sided subhepatic, near sagittal view, as described before. ${ }^{56}$ The ductus arteriosus was investigated both from a subcostal and a parasternal short axis view, and the Doppler velocimetry was carried out according to Musewe et al. ${ }^{8}$

The foramen ovale and the atrial shunting was visualised using subcostal insonation. The tricuspid regurgitation was recorded from an apical four-chamber view.

For descriptive statistics median and total range was used. $\chi^{2}$ tests were used to compare groups with regard to categorial variables. A p value of $<0.05$ was regarded as significant.

\section{Results}

Acceptable recordings from the ductus venosus was achieved in all participants. In healthy term neonates the DVFV showed a cephalic biphasic waveform directed from the portal sinus to the inferior caval vein (fig 1C).

In the study group, and in six infants with congenital heart defects, colour and pulsed Doppler signals in ductus venosus showed increased pulsation of the flow velocity pattern in all infants (fig 1A), compared with the other

Table 2 Demographic data, mean airway pressure, and number of infants with clinically significant reversed ductus venosus flow velocity (DVFV) during atrial contraction

\begin{tabular}{llllll}
\hline & $\begin{array}{l}\text { No of } \\
\text { Cases }\end{array}$ & $\begin{array}{l}\text { Birthweight (g) } \\
\text { Median (range) }\end{array}$ & $\begin{array}{l}\text { Gestational age (weeks) } \\
\text { Median (range) }\end{array}$ & $\begin{array}{l}\text { Mean airway pressure } \\
\left(\mathrm{cm} \mathrm{H}_{2} \mathrm{O}\right) \text { Median (range) }\end{array}$ & $\begin{array}{l}\text { Significant } \\
\text { reversed flow }\end{array}$ \\
\hline $\begin{array}{l}\text { Study group } \\
\text { Control group I }\end{array}$ & 16 & $2740(1470-4230)$ & $35(32-42)$ & $12(7.5-16.5)$ & $16 / 16$ \\
$\quad$ & & $3570(2900-4685)$ & $40(38-42)$ & & $0 / 50^{\star \star}$ \\
$\quad \begin{array}{l}\text { Subgroup IA } \\
\text { Subgroup IB }\end{array}$ & 33 & $1290(625-2100)$ & $31(24-32)$ & & $0 / 33$ \\
Control group II & 13 & $1905(1415-2495)$ & $34(32-35)$ & & $0 / 13$ \\
Control group III & 11 & $920(625-1720)$ & $27(24-31)$ & $9.3(5-14.6)$ & $6 / 11$ \\
\hline
\end{tabular}

${ }^{\star}$ Group differences highly significant (study group and control group III $v s$ other groups). $\star \star$ During the first day of life, reversed DVFV during atrial systole was observed in 10 infants. (Study group = neonates with PPHN, control group IA $=$ healthy term neonates, control group IB $=$ preterm neonates without
PPHN, control group IC $=$ preterm neonates with gestational age similar to that of study group, control group II $=$ mechanically PPHN, control group IC = preterm neonates with gestational age similar to that of study group, control group II = mechanically
ventilated neonates with increased intrathoracic pressure but without PPHN, control group III = neonates with congenital heart vefects and raised right atrial pressure). 

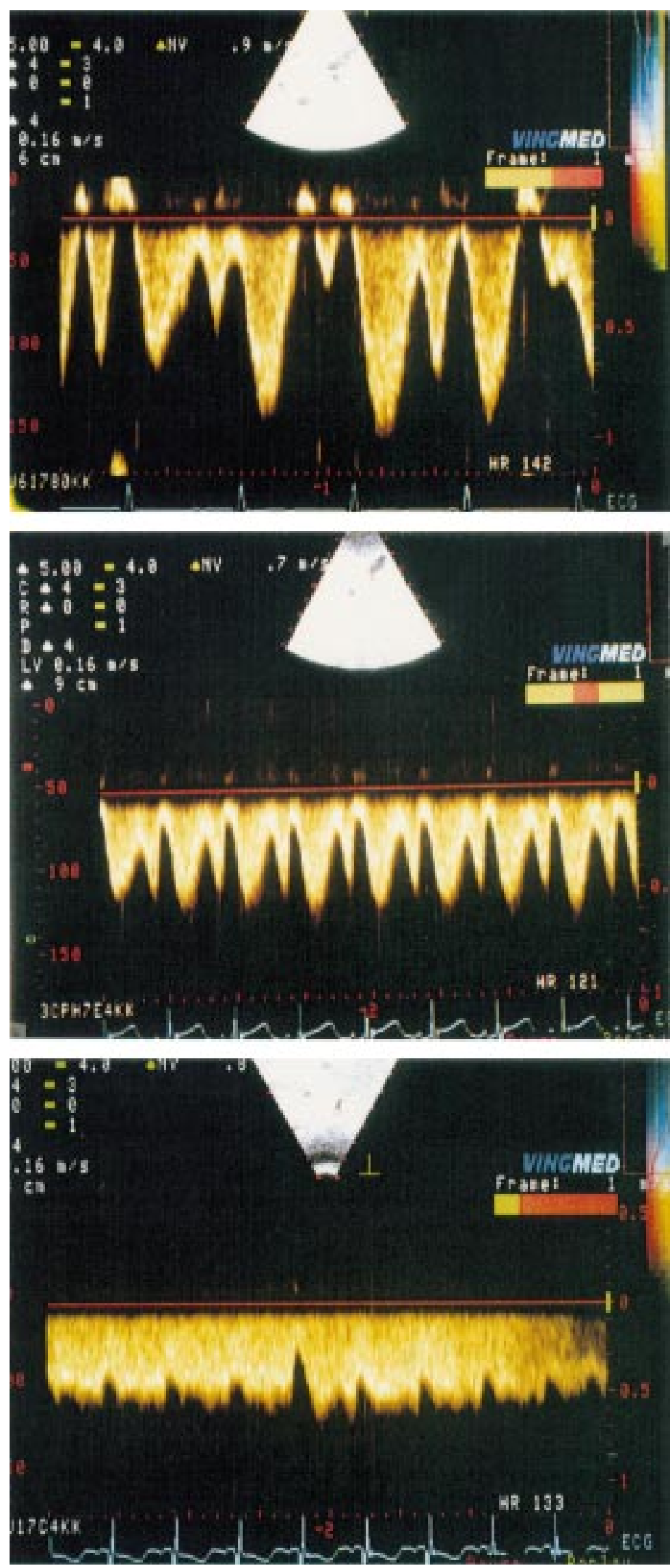

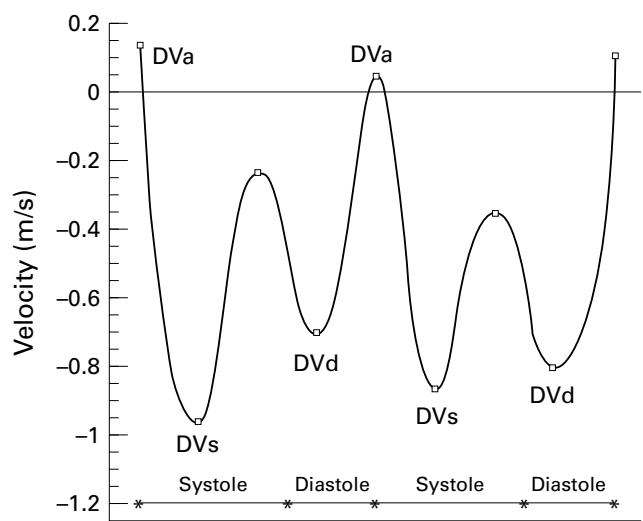

Figure 2 Schematic illustration of the ductus venosus flow velocity signals in infants with PPHN or high right atrial pressure. (DVa $=$ ductus venosus flow velocity at atrial contraction, $D V d=$ ductus venosus flow velocity in early diastole, $D V s=$ ductus venosus flow velocity in systole).

groups. In these neonates three DVFV components were identified during the cardiac cycles (fig 2).

A reversed DVFV signal during atrial contraction (DVa) was the most prominent finding, and was noted in all infants in the study group with PPHN, indicating that the central venous pressure during this short time interval exceeded the portal pressure. This reversed flow signal was independent of spontaneously or mechanical ventilation or what mode of ventilation the infant received. The same DVFV was found in the infants with congenital heart defects and increased right atrial pressure.

One peak of antegrade DVFV was observed during ventricular systole (DVs), which coincided with ventricular contraction and another peak of antegrade DVFV was found in early diastole (DVd), which coincided with the early phase of the ventricular diastole during passive filling. The DVs was always higher than the DVd.

When the pulmonary vascular resistance decreased as a result of treatment, the DVFV gradually changed to a normal pattern (figs $1 \mathrm{~B}$ and $1 \mathrm{C}$ ), one and four days after treatment.

None of the infants in the control groups I and II showed the typical reversed flow velocity signal in ductus venosus, as found in the PPHN group, even when the distending airway pressure was equal in both groups (mean airway pressure was similar in the study group and control group II) (table 2). The results were also independent of the mode of ventilation.

Figure 1 Colour and pulsed Doppler signals in ductus venosus from case 10 before and one and four days after treatment: (1A) Typical ductus venosus flow velocity signal in an infant with PPHN showing systolic and early diastolic peaks, and an abnormally reversed velocity during atrial contraction. Variation in the pattern reflects respiratory movements. (1B) Ductus venosus flow velocity signal, associated with a slightly increased pulmonary vascular resistance, maintains an increased pusatile pattern compared with normal. (1C) Cephalic biphasic ductus venosus flow velocity signal that has returned to normal after four days. 


\section{Discussion}

The flow velocity in an open ductus venosus reflects the portocaval pressure gradient and the pressure on the right side of the heart, ${ }^{9}$ while the flow velocity in ductus arteriosus reflects the aortico-pulmonary pressure gradient. $^{58}$ The normal DVFV typically has a peak during ventricular systole, a second peak during early diastole, and a nadir during atrial systole (fig 1C)..$^{5}$ A short reversed flow velocity signal is found in some children at the time of bidirectional shunting in ductus arteriosus during the first day of life when the pulmonary vascular resistance is still high. ${ }^{5}$

This study has shown that the DVFV is qualitatively different, with an increased pulsatile pattern and a noticeable retrograde signal during atrial contraction when the right atrial pressure is increased, as in neonates with PPHN or congenital heart defect with high right atrial pressure (fig $1 \mathrm{~A}$ and fig 2). This phasic change in DVFV which is associated with PPHN resembles the findings in fetuses with cardiac disease ${ }^{10}$ Moreover, it is similar to some of the components described experimentally by Appleton in pulmonary venous flow velocity, ${ }^{11}$ which reflects the high pressure in the left atrium.

Doppler estimated gradients have correlated closely with invasive measurements of the peak instantaneous gradient between the aorta and pulmonary artery in systole ${ }^{11}$ and with the maximal tricuspid regurgitant Doppler velocity. ${ }^{8}$ Bidirectional ductus arteriosus shunting with the right-to-left shunt occurring as a negative deflection in systole, and left-to-right shunting as a positive deflection, beginning in late systole and extending into late diastole, is found in infants with persistent ductus arteriosus and severe PPHN. ${ }^{12}{ }^{13}$ According to Musewe et al, suprasystemic pulmonary artery pressure is found when the duration of the right-to-left shunt in ductus arteriosus is $>$ $60 \%$ of the systole. ${ }^{8}$

Right atrial pressure is reflected in the central venous pressure. Superior caval vein flow velocity pattern in adults is similar to an inverted trace of the right atrial pressure. ${ }^{14}$ Studies have shown good correlation between the pressure measured in the superior caval vein compared with the inferior caval vein in animals ${ }^{15}$ and in patients without abdominal distention. ${ }^{16}{ }^{17}$ Superior caval vein and hepatic vein flow velocity patterns are also comparable with the velocity patterns of right atrial venous filling in healthy children. ${ }^{18}$

In PPHN the right atrial pressure is raised and the venous return is impaired. The increased pulmonary artery pressure is reflected in the ductus arteriosus velocity pattern. Similarly, the altered pressure is reflected in the blood flow velocity in the central veins, ductus venosus, and the hepatic veins. In adults atrial associated retrograde velocity is common in the central and hepatic veins, ${ }^{19} 20$ and a reversed hepatic flow velocity during systole is found in adults with atrial fibrillation and tricuspid regurgitation. ${ }^{21}$

Central venous pressure is correlated with mean airway pressure. ${ }^{15} 1722$ We have shown that a rise in mean airway pressure alone was not sufficient to cause reversed flow in the ductus venosus during atrial contraction in the way that PPHN does.

Ductus arteriosus closes earlier than ductus venosus. ${ }^{56}$ The tricuspid regurgitation can be difficult to evaluate in patients treated with mechanical ventilation and especially during high frequency oscillation ventilation. An optimal insonation view is difficult to obtain when the lungs are continuously distended and the ultrasonographic signals are disturbed due to the vibration of the thorax. Ductus venosus is viewed from a subcostal position and is less affected by the disturbances found with high frequency oscillation ventilation. It therefore seems to be a valuable diagnostic addition to Doppler echocardiography.

This study has shown a qualitatively altered ductus venosus flow velocity pattern, with an increased pulsatile pattern and a retrograde signal during atrial systole in infants with PPHN. This signifies that central venous pressure exceeds portal pressure during atrial contraction. Central venous pressure is not invasively monitored, but we suggest this simple sign of negative velocity deflection in the ductus venosus as a new non-invasive indicator of raised pressure in the right heart, which is particularly suitable when the ductus arteriosus is closed and high frequency mechanical ventilation makes an apical and parasternal investigation difficult.

1 Steinhorn RH, Millard SL, Morin FC. Persistent pulmonary hypertension of the newborn. Role of nitric oxide and 1995;22:405-28.

2 Kinsella JP, Abman SH. Recent developments in the pathophysiology and treatment of persistent pulmonary hypertension of the newborn. F Pediatr 1995;126:853-64.

3 Chan KL, Currie PJ, Seward JB, Hagler DJ, Mair DD, Tajik AJ. Comparision of three Doppler ultrasound methods in the prediction of pulmonary artery pressure. $7 \mathrm{Am}$ Coll Cardiol 1987;9:549-54.

4 Snider AR. The ductus arteriosus: A window for assessment of pulmonary artery pressure? $f \mathrm{Am}$ Coll Cardiol 1990;15:457-8.

5 Fugelseth D, Lindemann R, Liestøl K, Kiserud T, Langslet A. Ultrasonographic study of ductus venosus in healthy A. Ultrasonographic study of ductus ven
neonates. Arch Dis Child 1997;77:F131-4.

6 Fugelseth D, Lindemann R, Liestøl K, Kiserud T, Langslet A. Postnatal closure of ductus venosus in preterm infants $<32$ weeks. An ultrasonographic study. Early Hum Dev 1998:53:163-9.

7 Kiserud T. In a different vein: the ductus venosus could yield much valuable information. Ultrasound Obstet Gynecol 1997;9:369-72.

8 Musewe NN, Poppe D, Smallhorn JF, et al. Doppler echocardiographic measurement of pulmonary artery echocardiographic measurement of pulmonary artery
pressure from ductal Doppler velocities in the newborn. 7 Am Coll Cardiol 1990;15:446-56.

9 Kiserud T, Eik-Nes SH, Blaas H-G, Hellevik LR, Simensen B. Ductus venosus blood velocity and the umbilical circulation in the seriously growth retarded fetus. Ultrasound Med Biol 1994;20:225-32.

10 Kiserud T, Eik-Nes SH, Hellevik LR, Blaas H-G. Ductus venosus blood velocity changes in fetal cardiac diseases. $\mathcal{F}$ Matern Fetal Invest 1993;3:15-20.

11 Appleton CP. Hemodynamic determinants of Doppler pulmonary venous flow velocity components: new insights
from studies in lightly sedated normal dogs. $7 \mathrm{Am}$ Coll Cardiol 1997; 30:1562-74.

12 Musewe NN, Smallhorn JF, Benson LN, Burrows PE, Freedom RM. Validation of Doppler-derived pulmonary arterial pressure in patients with ductus arteriosus under different hemodynamic states. Circulation 1987;76:108191

13 Su B-H, Watanabe T, Shimizu M, Yanagisawa M. Echocardiographic assessment of patent ductus arteriosus shunt flow pattern in premature infants. Arch Dis Child 1997;77:F36-40

14 Froysaker T. Normal flow pattern in the superior vena cava in man during thoracotomy. Scand $\mathcal{F}$ Thorac Cardiovasc Surg 1972;6:22-32. 
15 Berg RA, Lloyd TR, Donnerstein RL. Accuracy of central venous pressure monitoring in the intraabdominal inferior
vena cava: a canine study. F Pediatr 1992;120:67-71.

16 Litmanovitch M, Hon H, Luyt DK, Dance M, Mathivha LR. Comparision of central venous pressure measurements in the intrathoracic and the intra-abdominal vena

17 cava in critically ill children. Anaesthesia 1995;50:407-10. Reda Z, Houri S, Davis AL, Baum VC. Effect of airway
pressure on inferior vena cava pressure as a measure of central venous pressure in children. $f$ Pediatr 1995; 126:961-5.

18 Meyer RJ, Goldberg SJ, Donnerstein RL. Superior vena cava and hepatic vein velocity patterns in normal children. Am f Cardiol 1993;15:238-40.

19 Appleton CP, Hatle LK, Popp RL. Superior vena cava and hepatic vein Doppler echocardiography in healthy adults. $\mathcal{F}$ Am Coll Cardiol 1987;10:1032-9.
20 Pennestri F, Loperfido F, Salvatori MP, et al. Assessment of tricuspid regurgitation by pulsed Doppler ultrasonography of the hepatic veins. $\mathrm{Am} \mathcal{F}$ Cardiol 1984;54:363-8

21 Sakai K, Nakamura K, Satomi G, Kondo M, Hirosawa K. Evaluation of tricuspid regurgitation by blood flow pattern in the hepatic vein using pulsed Doppler technique. Am Heart f 1984;108:516-23.

22 Lichtwarck-Aschoff M, Zeravik J, Pfeiffer UJ. Intrathoracic blood volume accurately reflects circulatory volume status in critically ill patients with mechanical ventilation. Intensive Care Med 1992;18:142-7.

23 Halck SW, Walther-Larsen S, Sanchez R. Measurement of central venous pressure after open heart surgery and effect of positive end expiratory pressure. Dan Med Bull 1991;38:181-2. 